\title{
Perception of Climate Change and Impact on Land Allocation and Income: Empirical Evidence from Vietnam's Delta Region
}

\author{
Ashok K. Mishra, Valerien O. Pede, and Gustavo A. Barboza
}

\begin{abstract}
Using a sample survey from Vietnam's M\&RRD, this study examines both the factors affecting smallholder households' perceptions of climate change, and the impact of climatic change on smallholders' income and land allocation decisions. Results show a significant and negative impact of perception of climate change on income of smallholder households. Smallholders with perceived climate changes reduce land allocated to paddy crop. Farmers make strategic decision to counter the negative effects of climate change by increasing the amount of rented land for paddy crop production, while at the same time decreasing the amount of owned land allocated to paddy crop.
\end{abstract}

Key Words: climate change, income, owned land, rented land, rice farming, smallholders

JEL codes: Q12, Q18, Q54

The agricultural sector in Vietnam accounts for 20 percent of the gross domestic product (GDP) and contributes to about 44 percent of the agriculture labor and 69 percent of the rural labor force. In the last 25 years, Vietnam's agricultural sector has made significant progress, specifically in increased food availability, which has enhanced food security on a national level, along with a significant

Ashok K. Mishra, Kemper and Ethel Marley Foundation Chair, Morrison School of Agribusiness, Arizona State University. Valerien O. Pede, Agricultural Economist, Social Sciences Division, International Rice Research Institute. Gustavo A. Barboza, Professor, Department of Administrative Science, Clarion University of Pennsylvania. Correspondence: Ashok K. Mishra, Kemper and Ethel Marley Foundation Chair, Morrison School of Agribusiness - Arizona State University. W.P. Carey School of Business = 235M Santan Hall - 7231 E Sonoran Arroyo Mall Mesa, AZ 85212 - Email: Ashok.K.Mishra@asu.edu.

This work was implemented as part of the CGIAR Research Program on Climate Change, Agriculture, and Food Security (CCAFS), which is carried out with support from CGIAR Fund Donors and through bilateral funding agreements. For details please visit https://ccafs.cgiar. org/donors. The views expressed are the authors' and do not necessarily represent the policies or views of any sponsoring agencies. The study was initiated as part of the Policy Information and Response Platform on Climate Change and Rice in ASEAN and its Member Countries (PIRRCA) Project under CCAFS. Authors would like to thank the Institute of Policy and Strategy for Agriculture and Rural Development (IPSARD) and the Vietnam National University of Agriculture (VNUA) for assisting in conducting the survey. They also would like to thank all the households who participated in the surveys.

Agricultural and Resource Economics Review 47/2 (August 2018) 311-335

(C) The Author(s) 2018. This is an Open Access article, distributed under the terms of the Creative

Commons Attribution licence (http://creativecommons.org/licenses/by/4.0/), which permits unrestricted re-use, distribution, and reproduction in any medium, provided the original work is 
reduction in overall poverty rates. With this in mind, the country has emerged as one of the world's leading exporters of agro-food commodities such as rice, tea, catfish, shrimp, and coffee. Despite these positive changes, the agricultural sector of Vietnam still displays a low quality of growth, as shown by a low farm income of smallholders, underemployment of agricultural workers, and an overall lack of fundamental technological or institutional innovation. Notably, agricultural growth within this context has been achieved through an increase in cropping areas or through a more intense use of inputs such as fertilizers, and natural resources such as water.

This growth path has made the agricultural sector more vulnerable to changes in external state-dependent conditions such as the climate change impacts of flooding, drought, and increased soil salinity. In this regard, the impacts of climate change are some of the most challenging obstacles for future agricultural development in Southeast Asia, particularly in Vietnam. Given Vietnam's high dependence on agricultural production for its overall economic development, climate change can have a substantial impact on the agricultural sector and related industries (Douben 2006). For instance, most crops grown, e.g., mainly rice, in the region are highly sensitive to higher (lower) temperatures, increased (reduced) rainfall variability, such as floods and droughts, and rising sea levels. All of these climate change-related shocks could reduce crop yields and threaten food security in Vietnam, while significantly affecting the livelihoods of smallholder farmers.

The negative effects of climate change could pose very serious problems for smallholder farms in Vietnam's Mekong River Delta (MRD) and Red River Delta (RRD), ${ }^{1}$ which are both major rice-producing regions in the country. As stated recently by Neumann et al. (2015) and Winsemius et al. (2015), countries in Southeast Asia will face severe effects from climate change. For example, Bangalore, Smith, and Veldkamp (2016) note that changes in the amount and seasonality of rainfall, along with rising sea levels up to 1 meter in low-lying deltas, will lead to excessive flooding and saltwater intrusion. These climate change events and the onset of severe droughts, such as those resulting from the El Niño weather phenomenon, will exacerbate the economic vitality of the MRD ${ }^{2}$ and RRD (M\&RRD) of Vietnam. Thus, it is safe to argue that extreme weather patterns like El Niño, droughts, storms, and floods increasingly cause slow-onset disasters that pose long-term problems for the global food supply, people's livelihoods, and the economic development of a country.

\footnotetext{
1 The RRD of Vietnam, one of the world's most densely populated deltas, dominates northern Vietnam and is already vulnerable to flooding events.

2 The Mekong Delta of Vietnam is one of the most productive agricultural areas in the world. About 80 percent of the Mekong Basin's population relies on natural resources for subsistence and livelihoods. Agriculture provides food security and livelihoods for approximately 60 percent of the Mekong River Basin's population.
} 
Additionally, Paavola (2008) and Gentle and Maraseni (2012) argue that climate change is forecasted to pose a major threat to food security and livelihoods in the near future. The combined impacts of flooding and increased saltwater intrusion could threaten the overall agricultural output of the two deltas (M\&RRD) in Vietnam, particularly its rice production capabilities, both in terms of suitable land and its related productivity. Climate change is also expected to have further implications for resource availability (land), income, and water in many other Southeast Asian countries $^{3}$ (Kim 2011). As noted, because of its geographical location, the M\&RRD is at high risk for flooding, strong winds, variability in rainfall, and saltwater intrusion from rising sea levels, which could all negatively affect the productivity of the land. The fact that climate change has and continues to play an important and increasingly permanent role in agricultural production in Vietnam (ADB, 2010) suggests the need to understand how farmers perceive climate change, and how it affects land allocation decisions (rented and owned) and the rice income of smallholders.

Therefore, the objective of this study is twofold: (1) to investigate the factors associated with perceived climatic change in the fragile M\&RRD ecosystem; and (2) to estimate the impact of perceived climatic change on land allocation to paddy and on smallholders' rice income. Climatic change in this study is defined as the observation of the increase in temperature, sea level, variability in rainfall, and incidence of drought experienced by smallholder households. In this study, we also differentiate the impacts of perceived climatic change on both owned and rented paddy land allocations. Furthermore, these objectives are accomplished using farm-level data from M\&RRD ecosystems as well as an econometric model that combines the strengths of endogenous treatment effects and the probit discrete-choice method. These models are estimated using a two-stage framework, with the first stage being the perception of climatic change by smallholder households specified as a probit model. The emphasis in the second stage is on the estimation factors affecting income, land allocation in paddy crop, owned land in paddy crop, and rented land in paddy crop. Notably, the binary indicator that identifies perception of climatic change is included in this equation, and a test to see if the binary indicator of climatic change by the smallholder household equals zero is employed to demonstrate the impacts on income, land allocation in paddy crop, owned land in paddy crop, and rented land in paddy crop. Furthermore, to determine the presence of unobservable heterogeneity, a test for the significance of the correction term for treatment selection bias is used to justify whether or not perceived climatic changes are correlated with income, land allocation in paddy, and owned and rented land in paddy allocation.

3 Francisco (2008) notes that Southeast Asian countries have seen significant changes in the frequency and intensity of extreme climate events associated with climate change. 
This rest of the paper is organized as follows. The next section explores the most relevant literature on climate change and its impact on agricultural production/productivity, household income, and related topics. The third section develops the conceptual framework for the development of our empirical analysis. The fourth section provides a detailed analysis of the data and corresponding empirical estimations. We conclude the last section with some highlights and policy recommendations.

\section{Literature Review}

A recent study by Kim (2011) notes that Asia is one of the most vulnerable regions to climate change. Particularly in Vietnam, agriculture could be affected by flooding, drought, saltwater intrusion, torrential rains, and typhoons (ADB, 2010), and as a result, crop yield could be reduced. ${ }^{4}$ The combined effect (negative) of climate change on yields and the high levels of farmer exposure to uncertainty are pervasive in the agricultural sector and in the overall development of the South Asian region (Yu et al. 2010). Several studies (see Thomas et al. 2007; Mertz et al. 2009; Yu et al. 2010; McKinley et al. 2015, among others) show that poor or uninformed perception of the effect of climate change results in farmers increasing their level of exposure to negative events and, consequently, paying dearly for their unpreparedness and ignorance in the form of lost income or damaged crops. Furthermore, a review of the literature on the topic of climate change shows that more attention has been paid to issues relating to climate change system modeling, climate change impacts, and adaptation and risk assessment. For instance, a recent study by McKinley et al. (2015) provides an assessment of the perception of climate change and, more importantly, gives evidence regarding the marked differences at the regional and national levels. Several studies, such as Li et al. (2013) and Abid et al. (2015), demonstrate that farmers make decisions regarding allocation of land as it relates to coping with changes in climate conditions based on their self-informed perceptions of how climate change may occur, either as increased droughts or flooding.

As noted, climate change can have multiple effects on the average growing conditions of crops. These variations away from the mean conditions create unexpected scenarios that affect land allocation, average yield, and the total loss of a growing season in extreme cases. Any of these variations, especially when not controlled for, could have pervasive effects to most farmers, particularly those that rely more heavily on rainfall as a main source of water. In this regard, Smajgl et al. (2015), for instance, indicate that the development of complementary strategies at the government level aim at

\footnotetext{
4 Rising sea levels and other effects of climate change on the coastal resources sector are projected for Southeast Asia (ADB, 2010), where a rise of one meter in sea level could put 7.8 million people at risk, including 11 percent of the population of Vietnam (Francisco, 2008).
} 
reducing the negative effects of events such as droughts, thus, providing more stable growing conditions for crops. Particularly, Smajgl et al. (2015) argue in favor of upstream management of reservoirs to ameliorate salinity intrusion resulting from severe drought years. In this context, management practices such as this would provide more stable conditions for farmers to continue growing their crops and, consequently, better match their climate change expectations with the actual events.

Regarding the development, planning, and implementation of government policies to counter the negative effects of climate change, Yu et al. (2010) argue in favor of policies particularly aimed at ethnic-minority and poor communes. Yu et al. (2010) argue that these practices could result in increased productivity and amelioration of negative effects deriving from climate change by reducing the unexpected variability of climate change on agricultural production. Furthermore, Morton (2017) concludes that local knowledge (or perception) of climate change can help in the effective and efficient adoption of management strategies to counterbalance the negative effects of climate change, particularly in agriculture production. Due to the inevitability of a changing climate and its adverse consequences-particularly when the variation is extreme, either through a severe drought or excessive flooding-it is relevant to better understand the impact on smallholders living in the fragile ecosystem of Vietnam's M\&RRD. For example, Yu et al. (2010) estimate that yield could decline as a negative consequence of future climate change in the range of 4.3 percent to 8.3 percent by 2050 in the MRD and a decline of 7.5 percent to 19.1 percent in the RRD regions. A related study of the RRD Symposium of 2016 indicates the presence of asymmetric efforts to understand the effects of climate change as the RRD suffers more from climate change, yet receives less attention than the MRD.

In the same study, Yu et al. (2010) argue that to counter the negative effects of climate change, modern technology and crop diversification must be tailored to promote an adaptation of change that is local in nature and, thus, considers spatial conditioning elements. In a similar fashion, McKinley et al. (2015) address issues of perception, accounting for differences at the local and national levels in Vietnam. Of particular interest is their assessment that policy formation centered on the effects of climate change on agricultural production, employment, and the overall level of economic development tends to follow a centralized, top-down approach. The authors note that the marked differences of the reported effects of climate change vary largely by group. This is to say that increased saline in the soil was reported by stakeholders as the most concerning effect of climate change. At the local level of data disaggregation, however, McKinley et al. (2015) note that in the MRD region the top three concerns were flood, drought, and rainfall. Smajgl et al. (2015) highlight the development of mitigating strategies, such as alternative livelihoods production activities away from farming, as the response of negative effects of climate change on agricultural production. The issue of response to climate change also extends to the role that the central 
government plays. For instance, McKinley et al. (2015) argue in favor of the development of salt-tolerant rice varieties, climate-smart land, and crop management as possible strategies to counter the negative effects of climate change, severe drought, and flooding.

Most recently, Chapman and Darby (2016) recommend adaptation policies in the M\&RRD in response to climatic changes. Particularly, Chapman and Darby (2016) emphasize the benefits of what they call a system dynamics approach. In this system, the authors argue that the primary focus is to assess the existent disparate of cross-disciplinary factors in the process of developing a controlling adaptation process to successfully increase efficiency and overall productivity. These results are particularly useful given the proliferation of a triple-cropping rice cultivation system, which while in the short run may increase food production and income, may in turn increase the exposure that poorer farmers experience as a result of potential increases in the price of fertilizer.

The review of the extant literature makes evident that adaptation is a key and fundamental response to climate change, particularly for regime-switching events and severe variations in climate conditions. For instance, Bryant et al. (2000) report that adaptation in agriculture is how the perception of climate change is translated into agricultural decision making. ${ }^{5}$ There have been several studies investigating factors that affect adaptation to climate change in the agricultural sector (see Adger et al. 2003; Deressa, Hassan, and Ringler, 2011; Below et al. 2012 among others). However, in the extant literature, relatively little attention has been devoted to the perceptions farmers hold on the effects of climate change and their impact on income and land allocation decisions. The observed differences between perceptions among stakeholders of the impact and strategic behavior resulting from climate change in Vietnam (McKinley et al. 2015) and the effects that central government imperatives have on household-level motivations and adaptation (Yu et al. 2010) becomes a relevant and timely field for research. Thus, our paper attempts to fill the gap in the understanding of the perception of climate change by smallholder households on rice income and land allocation decisions (both owned and rented land).

\section{Empirical Framework}

To estimate the effect of perceived climatic change on income, land allocated to paddy, and owned and rented land allocated to paddy, the endogenous treatment effect was used with a binary response (Vella and Verbeek, 1999).

\footnotetext{
5 Smith et al. (2000) and Adger et al. (2003) argue that adaptations, or particular adjustments in a system to better cope with external stress, are manifestations of adaptive capacity. Additionally, there are many forms of adaptations, including anticipatory or reactive, autonomous or planned, local or widespread, and technological, behavioral, financial, institutional and/or informational.
} 
The empirical model was estimated on a two-stage framework. In the first stage, the factors affecting the perceived climatic change by smallholders in MRD and RRD of Vietnam were investigated. Using consistent estimates from the first stage, an inverse Mills ratio (IMR) was calculated to account for potential treatment selection bias. The IMR along with the binary response on climate change and other variables were then included in the second stage in the rice income, land allocation decisions for paddy, and owned and rented allocation decisions for paddy. A detailed discussion on the econometric framework in each stage is discussed below.

\section{First Stage Estimation}

To model the perception of climate change by smallholders in the M\&RRD, the binary choice framework was employed. ${ }^{6}$ Notably, there were some smallholders who observed climate change and some who did not. The underlying model assessing perception of climate change is embedded in the psychometric (Fischhoff et al. 1978; Sjöberg 2000) and the cultural theory models (Dake 1991; Sjöberg 1997). Additionally, the cultural theory stresses that risk perception is a reflection of the social context in which an individual finds him or herself. Regardless, the argumentation indicates that the perception of climate change among farming communities or rural communities is driven by several socioeconomic and environmental factors (Sampei and Aoyagi-Usui 2009; Deressa, Hassan, and Ringler, 2011). These factors include farming experience, the age of the farmer, spouse, gender, household income, educational attainment, membership in environmental groups, access to media (Leiserowitz 2006), soil type, and geographical location $^{7}$ (Maddison 2006). Thus, the specification of the binary probit model describing the perception of climate change ${ }^{8}$ is shown as

$$
P_{c}^{*}=X^{\prime} \beta+\zeta ; P_{c}=1 \text { if } P_{c}^{*}>0, E(\zeta)=0 ; \operatorname{Var}(\zeta)=1,
$$

\footnotetext{
6 Because we have several indicators of perception of climate changes, as noted earlier in the text, one reviewer suggested using a multivariate probit regression framework in the first stage. Such estimation is not possible due to thinness of the data in each of the four indicators of perceived climate change. Further, in many cases, households experienced two, three, or four indicators of climate changes, not necessarily in the same period but over a 10-year period. Adaptation strategies considered by households are implemented as a response to climatic changes over time.

7 One reviewer noted that farm community characteristics - for example, social capital and extension contact - could influence the perception of climate change by operators and their spouses. Unfortunately, the survey questionnaire did not collect information on social capital, extension contact, access to/use of media, and participation in workshops/seminars. Future studies can investigate such influences on perception of climate change.

8 Climate change $=1$ if the smallholder household perceives, over time, incidences of increased temperature, increased sea level, increased variability in rainfall, and increased drought; and $=0$ otherwise.
} 
where $P_{c}^{*}$ is the latent variable that represents the probability/propensities of smallholder households to observe climate change (perceived); notice that this variable is not directly observed in the data. Instead, only the binary indicator allows us to specify if the smallholder perceives climate change over several years, i.e., increased temperature, rainfall, sea level, variability in rainfall, and drought. $X$ is a set of covariates associated with perceived climate changes. $\beta$ are parameters to be estimated. The error term $\zeta$ follows a standard bivariate normal distribution. Consistent estimates of Equation 1 can be obtained by applying the maximum likelihood estimation to the following log likelihood function:

$$
\log L=\sum_{i=1}^{n} \log \Phi\left[\left(2 P_{c}-1\right) X^{\prime} \beta\right],
$$

where $\Phi$ is the cumulative density function of the bivariate normal distribution. ${ }^{9}$

\section{Second Stage Estimation}

To examine the extent to which perceived climatic change may affect income, land allocation to paddy, and owned and rented land allocated to paddy, the endogenous treatment effects were incorporated. Here we follow the specification in Barrow et al. (1996), which posed that this model with endogenous treatment effects accounts for the fact that unobservable variables might be correlated with perceived climatic change, ${ }^{10}$ the level of rice income, and land allocation decisions (owned and rented land) of smallholders. To estimate the endogenous treatment effects model, two methods have been proposed in the literature, which include instrumental variable and control function methods. A detailed discussion of these two methods is found in Vella and Verbeek (1999). Specifically, Vella and Verbeek (1999) found that both methods generate consistent estimates; however, the control function method is preferable when it comes to gains in efficiency. Therefore, in our study, the control function method (CFM) was used.

CFM is an extension of the sample selection framework but with application to the entire sample. In order to correct self-selection bias, the generalized residual, generalized inverse Mills ratio (GIMR), was calculated for perceived climate change in the entire sample. Using Greene's (2012) approach, the

\footnotetext{
9 As pointed out by one reviewer, perception of climate change may also be influenced by their neighbor's perception. However, the survey did not query farmers on their neighbor's perception of climatic changes because this is beyond the scope of this study. We recognize this as a limitation for this paper, and we recommend future studies to take this into account.

10 We also investigated the correlation (using two-step residual inclusion (2SRI) method) between the residuals of perception and response equations and found no significance.
} 
GIMR in univariate probit model is shown as

$$
\operatorname{GIMR}=\left(2 P_{c}-1\right)^{*} \frac{\phi\left(2 P_{c}-1\right) X^{\prime} \beta}{\phi_{i}(.)} \Phi,
$$

where GIMR is the general residual of perceived climate change by smallholders. $\Phi($.$) and \Phi($.$) are the cumulative density function and$ probability density function of the standard normal distribution, respectively. Including GIMR in the income and land allocation (owned and rented), while also applying ordinary least squares method (OLS), results in consistent estimation (Vella and Verbeek, 1999). The estimated income, land allocation in paddy, and owned and rent land in paddy production is thus specified as

$$
Y_{i t}=\beta^{\prime} X_{i}+d_{c}{ }^{*} P_{c}+k_{c}{ }^{*} \mathrm{GIMR}+\mu_{i},
$$

where $Y_{i}$ is the outcome variable of smallholder household, $i$, and $t=$ four outcomes (rice income, land allocation in paddy, owned land allocation in paddy, and rented land allocation in paddy). $\beta$ is the vector of parameters to be estimated, $X_{i}$ contains exogenous variables, and $P_{c}$ is a binary indicator that specifies smallholders' perception of climate change. The estimated parameter, $d_{c}$, captures the effect of perceived climate change on the outcome variable of interest (rice income, land allocation to paddy, and owned and rented land allocated to paddy). Finally, the scalar, $\mu_{i}$, is the random error.

Finally, based on the consistent estimation of Equation 3, two issues are of interest. The first issue is whether or not perceived climate change has any significant effect on the outcome variables of smallholder households. Specifically, the null hypothesis $H_{0}: \quad d_{c}=0$ was statistically tested. Alternatively, testing $H_{0}: k_{c}=0$ provided the statistical evidence on whether or not there is a need to include the GIMR to correct for self-selection bias in the outcome equations.

\section{Data and Description of Variables}

The data for this study are original data collected by the International Rice Research Institute (IRRI) in collaboration with the Institute of Policy and Strategy for Agriculture and Rural Development (IPSARD) and the Vietnam National University of Agriculture (VNUA) as part of the Policy Information and Response Platform on Climate Change and Rice in ASEAN and its Member Countries (PIRRCA) Project. A total of 428 households were surveyed on climate change perceptions. Seven districts in three provinces of the MRD were selected as part of this survey, according to the following distribution: An Giang Province with 90 households, Bac Lieu Province with 64 households, and Tra Vinh Province with 60 households. In the RRD, two districts were selected: Thai Binh with 107 households and Nam Dinh with 
107 households. The survey areas for this study were selected based on prior knowledge of climate change issues specific to these locations. In the respective hierarchical order, communes, districts, and villages were selected following the same criteria. From a list of farmers with at least 10 years of farming experience at the commune level, the households were selected using a stratified random sampling procedure with the same number of respondents from each village.

The survey was conducted in the three provinces in the MRD under the supervision of IPSARD and in two provinces in the RRD under the supervision of VNUA. The five provinces included in this survey face various climate change issues. To illustrate the variety and possible extent of the climate change impact, let us look at some specific cases. First, the Bac Lieu is a coastal province with a coastline of $56 \mathrm{~km}$, a flat terrain, and tropical monsoon climate; it is one of the main rice-producing provinces in the MRD. Nevertheless, this province faces several climate change challenges, such as sea level rise and heavy rain. The sea level rise causes salt intrusion into paddy fields, which leads to crop losses, while heavy rains result in floods and also cause crop damage. Second, the Tra Vinh is another coastal province of the MRD also affected by sea level rise. Furthermore, in An Giang, the main climate change challenges are related to unusual rainfall patterns and frequent flood. In the RRD, Thai Binh and Nam Dinh are regions characterized by cold and hot temperatures, typhoons, cyclones, and floods.

Smallholder households' perceptions of climate change relate more to the increased variability and uncertainty of specific weather parameters rather than long-term climate change (Mertz et al. 2009). Some of these perceptions include the late onset of rains, shorter wet monsoon strong winds with excessive rains, more intense summer heat, and unpredictability in the patterns of the seasons. However, in this study of Vietnam's M\&RRD, the authors queried smallholder households (operators and spouses) on the severity of climate change over time. Specifically, they were queried over whether they had observed, consistently over time, increased temperature, increased sea levels, increased variability in rainfall, and increased incidences of drought. ${ }^{11}$

Descriptive statistics on the households involved in the surveys are presented in Table 1 . The average age in the survey is 50 years, and the male operator is slightly older than the spouse. The farming experience of both the operator and spouse is around 30 years, which is a long enough time frame to expect adequate judgments from them on perceived climate changes in their respective areas over the past 10 years. In addition, the data indicate that male operators in the survey have about three years' more farming experience than their spouses. This finding could also be linked to the age

\footnotetext{
11 Perceived climatic change variable $=1$ if the operator and spouse perceived any of the four indicators of climate change.
} 
Table 1. Variable Description and Descriptive Statistics

\begin{tabular}{lccccc}
\hline Variables & Obs & Mean & $\begin{array}{l}\text { Standard } \\
\text { Deviation }\end{array}$ & Min & Max \\
\hline Age of farm operator (years) & 428 & 52.41 & 10.92 & 28 & 86 \\
Age of spouse (years) & 428 & 48.60 & 10.87 & 22 & 78 \\
Education, operator (years) & 428 & 6.96 & 2.60 & 0 & 14 \\
Education, spouse (years) & 428 & 6.11 & 2.72 & 0 & 12 \\
Farming experience, operator (years) & 428 & 32.15 & 11.34 & 5 & 61 \\
Farming experience, spouse (years) & 428 & 29.07 & 11.61 & 2 & 62 \\
Total household size (\#) & 428 & 4.22 & 1.56 & 2 & 10 \\
Gender, head (1 = Male; 0 = female) & 428 & 0.96 & 0.17 & 0 & 1 \\
Total farm size (sq. m) & 428 & 12,121 & 15,090 & 540 & 143,000 \\
Total land allocated to paddy (sq. m) & 428 & 11,066 & 14,997 & 540 & 143,000 \\
Own land allocated to paddy (sq. m) & 428 & 9,593 & 1,4305 & 0 & 143,000 \\
Rented land allocated to paddy (sq. m) & 421 & 1,417 & 5,088 & 0 & 65,000 \\
Total income (million VND) & 396 & 97.35 & 155.61 & 0 & 1,760 \\
Rice income (million VND) & 426 & 80.50 & 150.82 & 0 & 1,760 \\
Ecosystem (1 = Irrigated; 0 = Rainfed) & 428 & 0.85 & 0.359 & 0 & 1 \\
\hline
\end{tabular}

Sources: Survey conducted by author(s).

gap between operators and spouses, which is roughly three years. In most households, male operators and spouses have six years of education, and in Vietnam, six years of formal education is equivalent to the completion of primary school. Furthermore, the average household size is four members, with the largest household reaching 10 members, and the majority of households are run by a male. Households in this survey have 1.2 ha of land on average, and the majority (about 90 percent) of this land is devoted to paddy production; however, in terms of land allocated to paddy production, owned land dominates rented land. Additionally, the majority of farmers grow rice in an irrigated environment. On average, households have a total income of 97 million VND, with the majority derived from rice production, which confirms once again the importance of rice production in the livelihoods of farmers in the delta regions.

\section{Results and Discussion}

In this section, we discuss the results of the factors affecting perceived climate change by smallholder households in Vietnam's M\&RRD, followed by the impact of perceived climate changes on income and land allocation decisions (owned and rented land) by smallholder households. 


\section{Factors Associated with Perceived Climate Changes}

In reference to the probit model (Table 2), McFadden's $R^{2}(0.10)$ is used to evaluate the fit of the model, with results indicating a reasonable fit of the model considering the cross-sectional nature of the data (Hensher and Johnson, 1981). Table 2 presents estimated parameters for the probit model of factors associated with perceived climate change by smallholder households in the M\&RRD. Incidentally, results show no significant influence of the traditional household characteristics (age, education, farming experience, household size, household head gender, farm size) on the probability of perceived climate change. Nevertheless, the type of ecosystem and provincial location of the farm and, by extension, smallholder household (dummy variable) have a significant influence on the probability of perceived climate change. For instance, smallholder household-irrigated ecosystems, compared to farms in the rainfed ecosystem, are more likely to perceive climate change (incidences of increased temperature, increased sea level, increased variability in rainfall, and increased drought). Our results indicate that being in an irrigated environment increases the probability of perceived climate changes by 9 percent. A plausible explanation could be that smallholder farms with irrigation facilities can better perceive climate change because they operate farms in a more controlled environment - perhaps needing to know what their irrigation requirements, costs, and profits are while planning their crop production. Additionally, smallholders who have irrigation facilities (irrigated ecosystems) may be relatively wealthy, and wealthy households tend to be more educated.

The location of the smallholder households and, by extension, their farms, is another important determinant of perceived climate change by farmers in the M\&RRD of Vietnam. Results in Table 2 reveal that farms located in the Bac Lieu, An Giang, and Tra Vinh provinces perceive a significantly higher probability of climate change than farms located in the base province of Nam Dinh. Results indicate that smallholder farms located in the Bac Lieu and Tra Vinh provinces, when compared to farms in the Nam Dinh province, are 11 percent and 8 percent more likely to perceive climate change, respectively. This is expected because the Bac Lieu and Tra Vinh provinces are located near the coast, so those farms have witnessed increasing sea levels over the past decade. Similarly, smallholder farms located in the An Giang provinces are 8 percent more likely to perceive climate change compared to smallholders located in the Nam Dinh province. The An Giang province, one the largest rice-producing provinces in the delta, witnesses frequent occurrences of fluvial floods. Coupled with the design of the dyke system for irrigation, flooding has raised major concerns for rice farmers over the past years. Notably, our findings are consistent with Chapman and Darby (2016). 
Table 2. Probit Estimates of Factors Affecting Perception of Climate Change

\begin{tabular}{|c|c|c|}
\hline \multirow[b]{2}{*}{ Dependent Variable } & \multicolumn{2}{|c|}{ Perceived Climatic Change } \\
\hline & Parameter Estimates & Marginal Effect $^{\mathbf{a}}$ \\
\hline \multirow[t]{2}{*}{ Constant } & -1.174 & \\
\hline & $(1.364)$ & \\
\hline \multirow[t]{2}{*}{ Age, operator (years) } & 0.023 & 0.003 \\
\hline & $(0.022)$ & $(0.003)$ \\
\hline \multirow[t]{2}{*}{ Age, spouse (years) } & -0.001 & -0.0002 \\
\hline & $(0.023)$ & $(0.003)$ \\
\hline \multirow[t]{2}{*}{ Education, operator (years) } & 0.029 & 0.004 \\
\hline & $(0.041)$ & $(0.006)$ \\
\hline \multirow[t]{2}{*}{ Education, spouse (years) } & 0.010 & 0.001 \\
\hline & $(0.042)$ & $(0.006)$ \\
\hline \multirow[t]{2}{*}{ Farming experience, operator (years) } & 0.002 & 0.0003 \\
\hline & $(0.019)$ & $(0.003)$ \\
\hline \multirow[t]{2}{*}{ Farming experience, spouse (years) } & -0.026 & -0.004 \\
\hline & $(0.021)$ & $(0.003)$ \\
\hline \multirow[t]{2}{*}{ Household size (number) } & -0.038 & -0.006 \\
\hline & $(0.055)$ & $(0.008)$ \\
\hline \multirow[t]{2}{*}{ Gender, head ( 1 = male; 0 = female $)$} & 0.047 & 0.007 \\
\hline & $(0.052)$ & $(0.094)$ \\
\hline \multirow[t]{2}{*}{ Total farm size (Log) } & 0.123 & 0.019 \\
\hline & $(0.123)$ & $(0.019)$ \\
\hline \multirow[t]{2}{*}{ Ecosystem $(1=$ irrigated; $0=$ rainfed $)$} & $0.471^{* * *}$ & $0.093^{* * *}$ \\
\hline & $(0.289)$ & $(0.067)$ \\
\hline \multirow[t]{2}{*}{ Bac Lieu Province } & $1.144^{* * *}$ & $0.109^{* * *}$ \\
\hline & $(0.470)$ & $(0.025)$ \\
\hline \multirow[t]{2}{*}{ An Giang Province } & $0.617^{*}$ & $0.078^{*}$ \\
\hline & $(0.359)$ & $(0.035)$ \\
\hline \multirow[t]{2}{*}{ Tra Vinh Province } & $0.659 * *$ & $0.076^{* *}$ \\
\hline & $(0.359)$ & $(0.029)$ \\
\hline \multirow[t]{2}{*}{ Thai Binh Province ${ }^{b}$} & 0.2614811 & 0.038 \\
\hline & $(0.215)$ & $(0.029)$ \\
\hline Number of observations & \multicolumn{2}{|c|}{428} \\
\hline Log-likelihood & \multicolumn{2}{|c|}{-137.20} \\
\hline
\end{tabular}


Table 2. Continued

Perceived Climatic Change

\begin{tabular}{lcc}
\cline { 2 - 3 } Dependent Variable & Parameter Estimates & Marginal Effect $^{\mathbf{a}}$ \\
\hline LR chi & 26.04 \\
Prob $>$ chi & 0.03 \\
Pseudo $R^{2}$ & 0.10 \\
\hline
\end{tabular}

${ }^{a}$ We report actual marginal effect.

${ }^{\mathrm{b}} \mathrm{Nam}$ Dinh province is used as a reference in the negative binomial regression

Single, double, and triple asterisks $(*, * * * * *)$ indicate significance at the 10 percent, 5 percent, and 1 percent level, respectively.

\section{Impact of Perceived Climate Changes on Outcome Variables}

The impact of perceived climate change by smallholder households, its impact on rice income (major crop of farmers in the M\&RRD), and total land allocated to paddy crop (Equation 4) is presented in Table 3. We use ordinary least square (OLS) to estimate the model, given that the primary objective of this study is to investigate the effects of perceived climate change on rice income and total land allocated to paddy crop. Table 3 presents the results on testing the above-mentioned hypothesis. In turn, Table 4 presents the test value under the null hypothesis that the perceived climate change by smallholders has no effect on rice income, and total land allocation under paddy crop is rejected. The results provide evidence that perceived climate changes by smallholders are important determinants of rice income and land allocation decisions on paddy crop.

Furthermore, it appears that smallholder households that perceive climate change are likely to have lower income from rice farming (Table 3). Our results show that households that perceive climate change have significantly lower rice income by about 3.3 percent less, compared to their counterparts. The decline in rice income can be attributed to the loss of paddy resulting from climate change phenomenon, such as intrusion of sea water in paddy fields, frequent floods, cold and hot temperatures, irregular rainfall pattern, and/or a combination of several of these elements. Our findings are consistent with previous studies such as Trung (2013), Thuy and Anh (2015), and Vien (2011). For instance, Thuy and Ahn (2015) in particular note that the MRD is very sensitive to flood and salinity because it is a low-lying coastal region.

An integral part of our study, as stated in the previous section, relates to the other critical issue of interest, referring to whether or not a self-selection bias occurs between perceived climate changes, income, and land allocation decisions. In this particular case, the test value on GIMR ranges from 3.10 to 14.58 and remains statistically significant at the 5 percent level of confidence. 
Table 3. Parameter Estimates for Impacts of Perceived Climate Changes on Income and Land Allocation to Paddy

\begin{tabular}{|c|c|c|c|c|}
\hline \multirow[b]{2}{*}{ Dependent Variables } & \multicolumn{2}{|c|}{ Rice Income } & \multicolumn{2}{|c|}{ Share of Land Allocated to Paddy } \\
\hline & $\begin{array}{l}\text { Parameter } \\
\text { Estimates }\end{array}$ & Elasticity at Means ${ }^{\mathbf{a}}$ & Parameter Estimates & Elasticity at Means \\
\hline \multirow[t]{2}{*}{ Constant } & $-659.936^{* * *}$ & & $79.941^{* * *}$ & \\
\hline & $(112.479)$ & & $(19.729)$ & \\
\hline \multirow[t]{2}{*}{ Age, operator (years) } & -0.060 & -0.039 & 0.139 & 0.085 \\
\hline & $(0.925)$ & $(0.602)$ & $(0.167)$ & $(0.102)$ \\
\hline \multirow[t]{2}{*}{ Education, operator (years) } & -3.356 & -0.290 & -0.115 & -0.009 \\
\hline & $(2.367)$ & $(0.205)$ & $(0.430)$ & $(0.035)$ \\
\hline \multirow[t]{2}{*}{ Farming experience, operator (years) } & -0.052 & -0.020 & -0.114 & -0.043 \\
\hline & $(0.941)$ & $(0.375)$ & $(0.169)$ & $(0.063)$ \\
\hline \multirow[t]{2}{*}{ Total household size (\#) } & 0.893 & 0.047 & 0.836 & 0.041 \\
\hline & $(3.978)$ & $(0.209)$ & $(0.715)$ & $(0.035)$ \\
\hline \multirow[t]{2}{*}{ Household head gender ( 1 = Male; $0=$ female $)$} & 31.997 & 0.385 & $10.845^{* * *}$ & $0.123^{* *}$ \\
\hline & $(32.535)$ & $(0.392)$ & $(5.919)$ & $(0.067)$ \\
\hline \multirow[t]{2}{*}{$\log ($ total farm size $)$} & $102.521^{* * *}$ & $1.273^{* * * a}$ & & \\
\hline & $(8.068)$ & $(1.175)$ & & \\
\hline \multirow[t]{2}{*}{ Ecosystem (1 = Irrigated; 0 = Rainfed $)$} & $71.295^{* * *}$ & $0.750^{* * *}$ & $13.264^{* * *}$ & $0.131^{* * *}$ \\
\hline & $(19.606)$ & $(0.212)$ & $(3.550)$ & $(0.035)$ \\
\hline \multirow[t]{2}{*}{ Bac Lieu Province } & $95.997^{* * *}$ & $0.179^{* * *}$ & $36.802^{* * *}$ & $0.064^{* * *}$ \\
\hline & $(33.694)$ & $(0.064)$ & $(6.1100)$ & $(0.010)$ \\
\hline An Giang Province & 7.735 & 0.020 & $26.701^{* * *}$ & $0.065^{* * *}$ \\
\hline
\end{tabular}


Table 3. Continued

\begin{tabular}{|c|c|c|c|c|}
\hline \multirow[b]{2}{*}{ Dependent Variables } & \multicolumn{2}{|c|}{ Rice Income } & \multicolumn{2}{|c|}{ Share of Land Allocated to Paddy } \\
\hline & $\begin{array}{l}\text { Parameter } \\
\text { Estimates }\end{array}$ & Elasticity at Means ${ }^{\mathbf{a}}$ & Parameter Estimates & Elasticity at Means \\
\hline & $(26.477)$ & $(0.069)$ & $(4.764)$ & $(0.011)$ \\
\hline \multirow[t]{2}{*}{ Tra Vinh Province } & 28.968 & 0.050 & $25.513^{* * *}$ & $0.041^{* * *}$ \\
\hline & $(27.956)$ & $(0.049)$ & $(5.075)$ & $(0.008)$ \\
\hline \multirow[t]{2}{*}{ Thai Binh Province ${ }^{\mathrm{b}}$} & $45.102^{* * *}$ & $0.142^{* * *}$ & $10.024^{* *}$ & $0.029^{* * *}$ \\
\hline & $(18.291)$ & $(0.058)$ & $(3.207)$ & $(0.009)$ \\
\hline \multirow[t]{2}{*}{ Climate change } & $-298.189 * *$ & $-3.295^{* *}$ & $-44.906^{* *}$ & $-0.466^{* *}$ \\
\hline & $(137.07)$ & $(1.531)$ & $(23.346)$ & $(0.242)$ \\
\hline \multirow[t]{2}{*}{ GIMR } & $164.601^{* *}$ & & $22.034^{*}$ & \\
\hline & $(73.327)$ & & $(12.524)$ & \\
\hline Test value $^{c}$ & $4.73^{* * *}$ & & $3.70^{* * *}$ & \\
\hline Test value $^{\mathrm{d}}$ & $13.06^{* * *}$ & & $3.10^{* * *}$ & \\
\hline Number of observations & 426 & & 428 & \\
\hline Adjusted $R^{2}$ & 0.44 & & 0.17 & \\
\hline
\end{tabular}

${ }^{\mathrm{a}}$ We report actual elasticity.

${ }^{\mathrm{b}} \mathrm{Nam}$ Dinh province is used as a reference in the negative binomial regression.

${ }^{c} \mathrm{H}_{0}$ : Climate change $=0$.

${ }^{\mathrm{d}} \mathrm{H}_{0}: \mathrm{GIMR}=0$.

Single, double, and triple asterisks ( $\left.{ }^{*}, * * * * *\right)$ indicate significance at the 10 percent, 5 percent, and 1 percent level, respectively. 
Table 4. Parameter Estimates for Impacts of Perceived Climate Changes on Owned and Rented Land Allocation to Paddy

\begin{tabular}{|c|c|c|c|c|}
\hline \multirow[b]{2}{*}{ Dependent Variables } & \multicolumn{2}{|c|}{$\begin{array}{l}\text { Share of Owned Land } \\
\text { Allocated to Paddy }\end{array}$} & \multicolumn{2}{|c|}{ Share of Rented Land Allocated to Paddy } \\
\hline & $\begin{array}{l}\text { Parameter } \\
\text { Estimates }\end{array}$ & Elasticity at Means & Parameter Estimates & Elasticity at Means \\
\hline \multirow[t]{2}{*}{ Constant } & $75.282^{* * *}$ & & -30.922 & \\
\hline & $(25.607)$ & & $(22.591)$ & \\
\hline \multirow[t]{2}{*}{ Age, operator (years) } & $0.496^{* *}$ & $0.360^{* *}$ & $-0.417^{* *}$ & $-1.828^{* *}$ \\
\hline & $(0.217)$ & $(0.157)$ & $(0.191)$ & $(0.854)$ \\
\hline \multirow[t]{2}{*}{ Education, operator (years) } & -0.045 & -0.004 & -0.193 & -0.112 \\
\hline & $(0.559)$ & $(0.053)$ & $(0.490)$ & $(0.286)$ \\
\hline \multirow[t]{2}{*}{ Farming experience, operator (years) } & -0.175 & -0.078 & 0.208 & 0.558 \\
\hline & $(0.220)$ & $(0.098)$ & $(0.194)$ & $(0.523)$ \\
\hline \multirow[t]{2}{*}{ Total household size (number) } & 0.351 & 0.020 & 0.021 & 0.007 \\
\hline & $(0.929)$ & $(0.054)$ & $(0.819)$ & $(0.290)$ \\
\hline \multirow[t]{2}{*}{ Household head gender ( $1=$ male; $0=$ female $)$} & $13.426^{* * *}$ & $0.180^{*}$ & -3.256 & -0.264 \\
\hline & $(7.682)$ & $(0.103)$ & $(6.728)$ & $(0.546)$ \\
\hline \multirow[t]{2}{*}{ Ecosystem ( 1 = irrigated; 0 = rainfed $)$} & $26.193^{* * *}$ & $0.307^{* * *}$ & $-10.722^{* * *}$ & $-0.758^{* * *}$ \\
\hline & $(4.607)$ & $(0.054)$ & $(4.040)$ & $(0.295)$ \\
\hline \multirow[t]{2}{*}{ Bac Lieu Province ${ }^{a}$} & $66.021^{* * *}$ & $0.136^{* * *}$ & $-30.743^{* * *}$ & $-0.391^{* * *}$ \\
\hline & $(7.930)$ & $(0.016)$ & $(7.002)$ & $(0.096)$ \\
\hline \multirow[t]{2}{*}{ An Giang Province } & $56.605^{* * *}$ & $0.164^{* * *}$ & $-30.547^{* * *}$ & $-0.546^{* * *}$ \\
\hline & $(6.183)$ & $(0.018)$ & $(5.464)$ & $(0.110)$ \\
\hline
\end{tabular}




\section{Table 4. Continued}

\begin{tabular}{|c|c|c|c|c|}
\hline \multirow[b]{2}{*}{ Dependent Variables } & \multicolumn{2}{|c|}{$\begin{array}{l}\text { Share of Owned Land } \\
\text { Allocated to Paddy }\end{array}$} & \multicolumn{2}{|c|}{ Share of Rented Land Allocated to Paddy } \\
\hline & $\begin{array}{l}\text { Parameter } \\
\text { Estimates }\end{array}$ & Elasticity at Means & Parameter Estimates & Elasticity at Means \\
\hline \multirow[t]{2}{*}{ Tra Vinh Province } & $58.855^{* * *}$ & $0.114^{* * *}$ & $-32.804^{* * *}$ & $-0.391^{* * *}$ \\
\hline & $(6.587)$ & $(0.012)$ & (5.813) & $(0.078)$ \\
\hline \multirow[t]{2}{*}{ Thai Binh Province } & $23.230^{* * *}$ & $0.081^{* * *}$ & $-13.593^{* * *}$ & $-0.283^{* * *}$ \\
\hline & $(4.162)$ & $(0.014)$ & (3.692) & $(0.081)$ \\
\hline \multirow[t]{2}{*}{ Climate change } & $-107.952^{* * *}$ & $-1.328^{* * *}$ & $102.217^{* * *}$ & $7.598^{* * *}$ \\
\hline & $(30.300)$ & $(0.373)$ & $(26.766)$ & $(2.119)$ \\
\hline \multirow[t]{2}{*}{ GIMR } & $58.733^{* * *}$ & & $-55.404^{* * *}$ & \\
\hline & $(16.255)$ & & $(14.387)$ & \\
\hline Test value $^{\mathrm{b}}$ & $12.69^{* * *}$ & & $14.58^{* * *}$ & \\
\hline Test value $^{c}$ & $13.06^{* * *}$ & & $14.58^{* * *}$ & \\
\hline Number of observations & 428 & & 421 & \\
\hline Adjusted $R^{2}$ & 0.28 & & 0.24 & \\
\hline
\end{tabular}

${ }^{a} \mathrm{Nam}$ Dinh province is used as a reference in the negative binomial regression.

${ }^{\mathrm{b}} \mathrm{H}_{0}$ : Climate change $=0$.

${ }^{\mathrm{c}} \mathrm{H}_{0}: \mathrm{GIMR}=0$.

Single, double, and triple asterisks $(*, * * * * *)$ indicate significance at the 10 prcent, 5 percent, and 1 percent level, respectively. 
These results provide robust and consistent evidence of a self-selection bias problem. In other words, the results of this analysis would be biased if the endogeneity between perceived climate change and rice income, total land allocated to paddy crop, and both owned and rented paddy land allocated to paddy crop of the smallholder rice farmer is not corrected. Thus, our original intuition is confirmed by the evidence, allowing us to provide a more robust analysis of the determinants and the dynamics of decision making in terms of land allocation as a result of climate change. This is, in itself, is a relevant piece of the analysis, because it indicates that the adjustment process spinning off from external events related to climate change has deeper roots that when not treated appropriately would yield unreliable results.

Because of the importance in the determination of rice income for smallholders, we study a set of other factors including farm size, ecosystem, and location of the farm. First, consistent with the economic theory, the parameter estimate on the farm size is significant at the 1 percent level of significance. More specifically, the results indicate that a 1 percent increase in farm size increases rice income by 1.3 percent. $^{12}$ Secondly, the coefficient on the ecosystem is positive and significant at the 1 percent level of significance (Table 3), indicating that smallholders in an irrigated environment have higher (7.5 percent higher) rice income compared to smallholders in the rainfed ecosystem (Table 3, column 3). This result is expected because farmers in the irrigated ecosystem have access to improved facilities and improved rice varieties (irrigation infrastructures, for example) as well as the fact that irrigated rice production is higher than nonirrigated rice production (or rainfed). Smallholders with irrigated rice production have the advantage of using better and more unified management practices, which leads to higher yields and, hence, increased income. Notably, our findings are consistent with Thi Ut and Kajisa (2006). Finally, our estimates accounting for farm location indicate that farms located in the Bac Lieu and Thai Binh provinces have higher rice incomes than in the Nam Dinh province. As noted earlier, the estimated coefficients yield consistent and robust evidence demonstrating that production of rice in the Nam Dinh province is frequently affected by climatic changes like flooding and rising sea levels, which consequently has a negative impact on farm income. Incidentally, this coefficient difference across provinces indicates that the level of exposure to negative effects deriving from climate change is higher in the Nam Dinh province.

Given the set of previous results, it follows that studying the impact of perceived climate change on land allocation in paddy crop is also an important issue to discuss. In this context, with regard to the factors affecting land allocation, our empirical evidence indicates that perceived climate change by smallholders has a negative and significant effect on land

12 Note that we report, in this case, the actual elasticity. 
allocation decisions for paddy crop. Parameter estimates on climate change are negative and statistically significant at the 1 percent level of significance (see Table 3, column 4), indicating that smallholders who perceive climate change tend to reduce land allocated to paddy by 0.5 percent. These results are complemented by the evidence in Table 3 , revealing regional differences when it comes to land allocation decisions for rice in the presence of climate change. Additionally, parameter estimates are positive and significant for farms located in Bac Lieu, An Giang, Tra Vinh, and Thai Binh provinces. At the marginal level, we observe a 3 percent to 6 percent increase in total land allocated to paddy crop in these regions, compared to the reference province of Nam Dinh. As expected, irrigated ecosystems have more land allocated to paddy. Finally, the coefficient on the household head ( $=1$ if male) is positive and significant, indicating that male-headed households, as compared to female-headed households, tend to allocate more land (1.2 percent) to paddy crop in the presence of perceived climate changes. A plausible reason could be that men tend to be overconfident, thinking that they can predict and handle the future, while women are more willing to adapt their strategies and behavior (Brown-Kruse and Hummels 1993; Patt, Dazé and Suarez, 2007).

Finally, we investigate if there are any differences in the allocation of land to paddy crop by land ownership. To accomplish this, the total land allocated to paddy crop is broken down into owned and rented rice land. Parameter estimates of the two estimated modes are shown in Table 4. Interestingly, the estimation results for owned land allocated to paddy crop remain consistent but lower in magnitude with those obtained in the total land allocated to paddy. One exception in this set of findings is that older (age of the operator) male operators (positive and significant coefficient on head of household) tend to allocate more of their owned land to paddy production. This finding could be due to the fact that owned land allocated to rice production represents a major share of the total land allocated to paddy crop. Additionally, Table 4 shows that parameter estimates are positive and significant for farms located in Bac Lieu, An Giang, Tra Vinh, and Thai Binh provinces. Results indicate a 1.2 percent to 1.8 percent increase in owned land allocated to paddy crop in these three provinces, compared to the reference province of Nam Dinh.

Finally, column 5 of Table 4 presents the parameter estimates of the model of rented land allocated to paddy crop in the presence of perceived climate change by smallholders. In this case, we see the sign on the coefficient of perceived climate change is reversed but significant at the 1 percent level of significance. Findings indicate that smallholders who perceive climate change tend to allocate more land to paddy crop, but the land is rented. We hypothesize that this result could be a risk management strategy for the smallholder households given the incidence of climate change in their region. In this context, it is pertinent to recall that in Vietnam, lands owned by farmers are, in general, allocated by the government who manages the agricultural land system. These lands cannot be used for other crops besides 
rice without permission from the government. More precisely, the legislation based on Article 134 of the "Vietnam Land Law No. 45/2013/QH13" about land for rice cultivation in Vietnam indicates the State develops policies to protect land for rice cultivation and to limit the change from the purpose of rice cultivation to other nonagricultural purposes (Socialist Republic of Vietnam, 2013). ${ }^{13}$

Therefore, with the increasing challenge of climate change in their region, farmers are more likely to seek rentable land that is less affected by natural disasters such as flooding and rising sea levels. Even though rice income decreases as a result of perceived climate change, smallholders still have a comparative advantage in growing rice, as it requires less investment (human capital and experience) and is a source of more stable income. Importantly, farmers still prefer to use the rented land for rice production. A recent article published in the Viet Nam News on August 6, 2013 entitled, "Poor Returns Drive Rice Farmers From Land," reveals the increasing trend of smallholders waiving their land-use rights to migrate and look for off-farm jobs in the city as a result of low return from paddy production. This article has stressed that this phenomenon is particularly occurring in several provinces of the RRD (Viet Nam News 2013). While some farmers are abandoning their land for off-farm jobs, those who want to remain in the rice production business have the opportunity to rent land, especially if the land is located in areas less affected by climate change. Indeed, these findings show that smallholders are astute in using their recourses carefully in that they reduce owned land allocated to paddy crop production while increasing the use of rented land in paddy crop production. There are also social welfare implications directly deriving from land ownership changes and land reallocation among smallholder farmers resulting from climate change. We believe that these last sets of topics are interesting fields of future research. Climate change appears to have larger implications that have received little attention. Because of Vietnam's geographic location and its large and dominant position in world rice production, our study provides relevant lessons useful to understand the dynamics of climate change on agricultural production, land allocation, and smallholders' income.

\footnotetext{
13 In case it is necessary to change a certain area of rice cultivation to another purpose, the State takes measures to supplement such land area or improve the efficiency in using the land for rice cultivation. The State adopts policies to support and invest in the construction of infrastructure and application of modern science and technologies into the areas planned for highproductivity and high-quality rice cultivation. Those who use land for rice cultivation shall improve and increase the fertility of the soil. They may not use that land for planting perennial trees, afforestation, aquaculture and salt production, or for nonagricultural purposes without permission by competent state agencies. People who are allocated or leased land by the State for nonagricultural purposes currently used for wet rice cultivation, shall pay a certain amount of money under the Government's regulations for the State to supplement the lost area of wet rice cultivation land or improve efficiency in using land for rice cultivation "Vietnam land Law No. 45/2013/QH13."
} 


\section{Conclusions and Policy Implications}

Climate change presents major environmental challenges for agricultural-based countries such as Vietnam and nearby neighbors. Climate change effects are manifested as strong fluctuations in rainfall, increased sea levels, increased soil salinity, increased temperatures, increased incidences of drought, and increased variability in rainfall. With global climate change, the impact and frequency of extreme state-dependent weather events are expected to intensify. Vietnam's M\&RRD are the most productive region of the country; however, agriculture has been under significant pressure because these regions are affected by natural disasters and climatic changes. The negative effects of these events have further increased as a result of agricultural expansion into more vulnerable areas. To this extent, relatively little is known regarding how smallholders perceive climate change and how it affects their income and land allocation to paddy crop. To bridge this gap, our study contributes to the literature by examining the factors affecting the perception of climatic change and how perceived climate change by smallholder households affects total land allocated to paddy crop production and, consequently, rice income. Notably, using a two-stage modeling approach, we pay particular attention to both owned and rented land allocations to paddy crop production. Using farm household level data from Vietnam's M\&RRD, we find that regional location of the farm has a significant impact on the perception of climate change.

Our findings reveal that indeed the perception of climate change has a negative and significant impact on rice income and total land allocated to paddy crop; yet, we also find that smallholders tend to allocate less owned land to paddy crop and, in turn, allocate more of the rented land to paddy. Additionally, we find a significant reversal of the results for older farmers, where older farmers are likely to keep allocating more of their owned land to paddy crop and less rented land to paddy crop. Our study underscores the importance of the perception of climate change and how smallholders are affected - whether it be a loss of income or how smallholders allocate land to rice production. As climate change affects their livelihood, smallholders respond in a way that is consistent with economic theory. It is important to note that as climate change continues to affect smallholders' livelihoods, increases in land allocation to new areas and provinces and increased deforestation may occur. This may become detrimental to the environment. Therefore, the call for appropriate policies and strategies to cope with the climate change challenges is significant.

Our study provides robust evidence that smallholder strategies relating to land allocation are based on their perceptions of climate change. Given that perceptions can be subjective, designing appropriate systems to provide smallholder households with historical and real-time climate information could also help households effectively plan their coping strategies when it comes to their own livelihoods and land allocation decisions. The merger of 
smallholder perceptions with local-driven policies would be useful to reduce the variability of farm incomes and increase the livelihoods of smallholders while increasing overall food security.

Our empirical analysis on the perceptions of climate change by farmers and their spouses provides some very relevant results. However, by the same token, our research indicates that further exploration on how expectations of climate change are formed is a relevant future field of study. For instance, it is of relevance to understand if farmers act the same way in the presence of droughts and flooding expectations. In addition, it is relevant to study the degree of information asymmetries that different farmers may have and how this could affect farming decisions on owned and rented land. Furthermore, it remains unclear if there is a threshold in the perception of climate change upon which farmers make their planting decisions. Additionally, do farmers perceive that small climate change variations might only have minor effects on crops and, thus, make no changes to planting decisions, or if the event(s) is expected to be large enough, does the farmer act?

In other words, an interesting research field is to evaluate the degree of variation on climate change perception that triggers a response from the farmer to produce or not and whether or not this perception is accurate. If the perception of the event is correct and the farmer assesses the negative effect correctly, then the farmer has protected him/herself from the negative event. However, if the perception is erroneous, then the farmer increases his exposure to the negative event or loses income when the negative event would have only had a minor effect on overall crops. Thus, the perception of climate change could go either way, and correctly assessing these differences in these events is a primary point of interest when understanding how farmers create their perceptions. Finally, it is also relevant to assess how (in) accurate are the expectation formation processes of climate change in relation to the actual climate events. All these research avenues are beyond the scope of the current research.

\section{References}

Abid, M., J. Scheffran, U.A. Schneider, and M. Ashfaq. 2015. "Farmers' Perceptions of and Adaptation Strategies to Climate Change and Their Determinants: The Case of Punjab Province, Pakistan." Earth System Dynamics 6(1): 225-243.

Adger, W.N., S. Huq, K. Brown, D. Conway, and M. Hulme. 2003. "Adaptation to Climate Change in the Developing World." Progress in Development Studies 3(3): 179-195.

Asian Development Bank. 2010. Ho Chi Minh City adaptation to climate change. Mandaluyong City, Philippines: Asian Development Bank. https://www.adb.org/sites/default/files/ publication/27505/hcmc-climate-change-summary.pdf. Accessed June 21, 2017.

Bangalore, M., A. Smith, and T. Veldkamp. 2016. Exposure to Floods, Climate Change, and Poverty in Vietnam. Policy research working paper; no. WPS 7765. Washington, DC: World Bank Group.

Barrow, E., M. Hulme and M. Semenov. 1996. "Effect of Using Different Methods in the Construction of Climate Change Scenarios: Examples from Europe." Climate Research 7: 195-211. 
Below, T.B., K.D. Mutabazi, D. Kirschke, C. Franke, S. Sieber, R. Siebert, and K Tscherning. 2012. “Can Farmers' Adaptation to Climate Change Be Explained by Socio-Economic HouseholdLevel Variables?" Global Environ. Change 22(1): 223-235.

Brown-Kruse, J., and D. Hummels. 1993. "Gender Effects of Laboratory Public Goods Contributions: Do Individuals Put Their Money Where Their Mouth is?" Journal of Economic Behavior and Organization 22(3): 255-267.

Bryant, C.R., B. Smit, M. Brklacich, T.R. Johnston, J. Smithers, Q. Chiotti, and B. Singh. 2000. "Adaptation in Canadian Agriculture to Climatic Variability and Change." Climate Change 45(1): 181-201.

Chapman, A., and S. Darby. 2016. "Evaluating Sustainable Adaptation Strategies for Vulnerable Mega-Deltas Using System Dynamics Modelling: Rice Agriculture in the Mekong Delta's An Giang Province, Vietnam." Science of the Total Environment 559: 326-338.

Dake, K. 1991. "Orienting Dispositions in the Perception of Risk." Journal of Cross-Cultural Psychology 22(1): 61-82.

Deressa, T.T., R.M. Hassan, and C. Ringler. 2011. "Perception of and Adaptation to Climate Change by Farmers in the Nile Basin of Ethiopia." Journal Agricultural Sciences 149(1): 23-31.

Douben, K.J. 2006. "Characteristics of River Floods and Flooding: A Global Overview, 19852003." Irrigation Drain System 55(1): 9-21.

Fischhoff, B., P. Slovic, S. Lichtenstein, S. Reas, and B. Combs. 1978. "How Safe is Safe Enough? A Psychometric Study of Attitudes towards Technological Risks and Benefits." Policy Sciences 9(2): 127-152.

Francisco, H. 2008. "Adaptation to Climate Change: Needs and Opportunities in Southeast Asia." ASEAN Economic Bulletin 25(1): 7-19. Available at http://web.idrc.ca/uploads/ user-S/12187839501ISEAS(HF).pdf (accessed July 12, 2016).

Gentle, P., and T.N. Maraseni. 2012. "Climate Change, Poverty, and Livelihoods: Adaptation Practices by Rural Mountain Communities in Nepal." Environmental Science and Policy 21: $24-34$.

Greene, W. 2012. "Econometric Analysis", 7th ed., Pearson, Upper Saddle River, NJ.

Hensher, D. A. and L.W. Johnson. 1981. "Applied Discrete-choice Modelling" Croom Helm, Andover, Hants.

Kim, S.Y. 2011. "Public Perceptions of Climate Change and Support for Climate Policies in Asia: Evidence from Recent Polls." The Journal of Asian Studies 70(2): 319-331.

Leiserowitz, A. 2006. "Climate Change Risk Perception and Policy Preferences: The Role of Affect, Imaginary, and Values." Climatic Change 77(1): 45-72.

Li, C., Y. Tang, H. Luo, B. Di, and L. Zhang. 2013. “Local Farmers' Perceptions of Climate Change and Local Adaptive Strategies: A Case Study from the Middle Yarlung Zangbo River Valley, Tibet, China." Environmental Management 52(4): 894-906.

Maddison, D. 2006. "The Perception of and Adaptation to Climate Change in Africa," CEEPA Discussion Paper No. 10. Pretoria, South Africa: Centre for Environmental Economics and Policy in Africa.

McKinley, J., C. Adaro, V.O. Pede, T. Setiyono, T.C. Thang, D.L. Huong, N.T. Kien, E. Quicho, M. Sheinkman, and R. Wassman. 2015. "The current state of climate change perceptions and policies in Vietnam: 2014 report, CCAFS Report." CGIAR Research Program on Climate change, Agriculture and Food Security (CCAFS). Copenhagen, Denmark.

Mertz, O., C. Mbow, A. Reenberg, and A. Diouf. 2009. “Farmers' Perceptions of Climate Change and Agricultural Adaptation Strategies in Rural Sahel." Environmental Management 43(5): 804-816.

Morton, J. 2017. "Climate Change and African Agriculture: Unlocking the Potential of Research and Advisory Services." In: F Nunan ed., Making Climate Compatible Development Happen. Routledge, Oxon, UK, pp. 87-113.

Neumann, J. E., K.A. Emanuel, S. Ravela, L.C. Ludwig and C. Verly. 2015. "Risks of Coastal Storm Surge and the Effect of Sea Level Rise in the Red River Delta, Vietnam." Sustainability 7(6): 6553-6572. 
Paavola, J. 2008. "Livelihoods, Vulnerability and Adaptation to Climate Change in Morogoro, Tanzania." Environmental Science Policy 11(7): 642-654.

Patt, A., A. Dazé, and P. Suarez. 2007. "Gender and Climate Change Vulnerability: What's the Problem, What's the Solution?" Paper presented at the International Women Leaders Global Security Summit, 15-17 November 2007, New York.

Sampei, Y., and M. Aoyagi-Usui. 2009. "Mass-Media Coverage, its Influence on Public Awareness of Climate-Change Issues, and Implications for Japan's National Campaign to Reduce Greenhouse Gas Emissions." Global Environmental Change 19(2): 203-212.

Sjöberg, L. 1997. "Explaining Risk Perception: An Empirical and Quantitative Evaluation of Cultural Theory." Risk Decision and Policy 2(2): 113-130.

- 2000. "Factors in Risk Perception." Risk Analysis 20(1): 1-11.

Smajgl, A., T.Q. Toan, D.K. Nhan, J. Ward, N.H. Trung, L.Q. Tri, V.P.D. Tri, and P.T. Vu. 2015. "Responding to Rising Sea Levels in the Mekong Delta." Nature Climate Change 5(2): 167-173.

Smith, K., C.B. Barrett, and P.W. Box. 2000. "Participatory Risk Mapping for Targeting Research and Assistance: with an Example from East African Pastoralists" World Development 28(11): 1945-1959.

Thi Ut, T., and K. Kajisa. 2006. "The Impact of Green Revolution on Rice Production in Vietnam." The Developing Economies 44(2): 167-89.

Thomas, D., C. Twyman, H. Osbahr, and B. Hewitson. 2007. "Adaptation to Climate Change and Variability: Farmer Responses to Intra-Seasonal Precipitation Trends in South Africa." Climatic Change 83(3): 301-322.

Thuy, N., and H.H. Anh. 2015. "Vulnerability of Rice Production in Mekong River Delta Under Impacts From Floods, Salinity and Climate Change." International Journal on Advanced Science Engineering Information Technology 5(4): 272-279.

Trung, P.T. 2013. "Climate Change and its Gendered Impacts on Agriculture in Vietnam." International Journal of Development and Sustainability 2(1): 52-62.

Vella, F. and M. Verbeek 1999. "Estimating and Interpreting Models with Endogenous Treatment Effects." Journal of Business \& Economic Statistics 17(4): 473-78.

Vien, T.D. 2011. "Climate Change and its Impact on Agriculture in Vietnam." Journal of the International Society for Southeast Asian Agricultural Sciences 17(1): 17-21.

Viet Nam News. 2013. "Poor returns drive rice farmers from land." Available at http:// vietnamnews.vn/society/243087/poor-returns-drive-rice-farmers-from-land.html\# gxo7qwxERAT7e7Xf.97 (accessed May 30, 2017).

Socialist Republic of Vietnam. 2013. "Vietnam land Law No. 45/2013/QH13" Available at http://vietnamlawenglish.blogspot.com/2013/11/vietnam-land-law-2013-law-no452013qh13.html (accessed June 27, 2018).

Winsemius, H.C., J.C.J.H. Aerts, L.P.H. van Beek, M.F.P. Bierkens, F.P. Marc, A. Bouwman, B. Jongman, J.C.J. Kwadijk, W. Ligtvoet, P.L. Lucas, D.P. van Vuuren, P.J. Ward. 2015. "Global Drivers of Future River Flood Risk." Nature Climate Change 6(4): 381-385.

$\mathrm{Yu}$, B., T. Zhu, C. Breinsinger, and N. Manh Hai. 2010. "Impacts of Climate Change on Agriculture and Policy Options for Adaptation." IFPRI Discussion Paper 01015. 